\title{
TENDÊNCIAS COMPETITIVAS DA COMIDA DE RUA: ESTUDO COMPARATIVO ENTRE DOIS FOOD PARKS E SEUS CONSUMIDORES.
}

\author{
Júlio César Ferreira Lima ${ }^{1}$, Susana Dantas COelho $^{1}$, Wellington Moura de Lima ${ }^{1}$ \\ ${ }^{1}$ Instituto Federal de Educação, Ciência e Tecnologia do Ceará - IFCE \\ <julioepedrita@gmail.com><susana.dantas09@gmail.com><wmoura41@gmail.com> \\ DOI: <https://doi.org/10.21439/conexoes.v14i4.1534>
}

\begin{abstract}
Resumo. Nas últimas décadas, mudanças ocorridas no estilo de vida das pessoas foram responsáveis por transformações na alimentação cotidiana mundial. A combinação da agitação diária, de programas gastronômicos de TV de alcance internacional e da influência de culturas diversas, resultado da globalização, fez com que novas formas de se alimentar despontassem. Os food parks surgiram como uma proposta gastronômica para a comida de rua. Esse estudo teve como objetivo geral comparar o potencial gastronômico e o público de 2 food parks. Como objetivos específicos, buscou-se diferenciar as estruturas físicas de um food park de Fortaleza e de um food park de São Paulo; estabelecer o perfil socioeconômico dos consumidores; e contrastar o perfil gastronômico desses consumidores. Optou-se por uma pesquisa com análise quali-quantitativa, de caráter exploratório, utilizando como método de procedimento um estudo de caso comparativo, tendo como instrumento de pesquisa um questionário aplicado entre os meses de janeiro e março de 2017. Os resultados demonstraram que havia diferenças estruturais entre os dois food parks. Por sua vez, o público foi em grande parte formado por solteiros entre $20 \mathrm{e}$ 40 anos de idade, se autodenominando possuidores de preferência gastronômica multicultural moderna e apoiadores da continuidade desse nicho gastronômico.
\end{abstract}

Palavras-chaves: Gastronomia. Tendências. Comida de rua. food parks. Consumidores.

\begin{abstract}
In the last decades, changes in people's lifestyles have been responsible for transformations in the daily diet worldwide. The combination of day-to-day agitation, internationally-acclaimed TV programs and the influence of diverse cultures, result of globalization, has influenced new ways of feeding. Food parks emerged as a gastronomic possibility for the street food. This study compared the gastronomic potential and the public of 2 food parks. As specific objectives, we sought to differentiate the physical structures of a food park in Fortaleza and a food park in São Paulo; to establish the socioeconomic profile of consumers; and to contrast the gastronomic profile of these consumers. Therefore, an exploratory study was conducted with a qualitative and quantitative analysis, using as a method of procedure a comparative case study, having a questionnaire as a research instrument, which was applied between January and March 2017. The results showed that there were structural differences between the two food parks. The majority of the public was constituted by single people between 20 and 40 years of age, admitting they were the owners of a modern multicultural gastronomic preference and supporters of the continuity of this street food niche.
\end{abstract}

Keywords: Gastronomy. Tendencies. Street food. Food parks. Consumers. 


\section{INTRODUÇÃO}

Nas últimas décadas, com a agitação diária, com o melhor aproveitamento do tempo livre e com o surgimento de programas gastronômicos competitivos televisionados, as pessoas vêm tendo contato mais próximo com culturas gastronômicas diferentes das habituais. Essas novas práticas instigam ao conhecimento de pratos providos de cores, sabores e texturas.

Nesse cenário de mudanças e transformações gastronômicas, novas propostas de oferta de alimentação ganharam visibilidade. Entre elas, encontra-se a comida de rua, bastante habitual em grandes cidades como Londres, Nova Iorque, Cidade do México, São Paulo, Paris, entre outras. A comida de rua ganhou nos últimos anos um reforço com a estilização e difusão dos food trucks 1 representantes principais desse tipo de alimentação. Os food trucks são normalmente veículos de porte pequeno ou médio adaptados para preparação, armazenamento e comercialização de alimentos e bebidas, podendo circular facilmente pelas vias urbanas sem a obrigatoriedade de um ponto fixo.

Os food trucks se posicionaram inicialmente no comércio gastronômico como uma oferta itinerante que buscava os clientes e com preços acessíveis por servir os produtos na rua e geralmente no estilo take awa ${ }^{2}$ Destarte, comidas características de várias culturas começaram a ser comercializadas nesses estabelecimentos e passaram a fazer parte do cotidiano de um maior número de pessoas. Assim, a conotação utilizada para comida exótica começa a diminuir entre os frequentadores desses ambientes, que não mais precisavam adentrar restaurantes e pagar um preço normalmente mais elevado.

Depois de ganhar fama na América do Norte e na Europa, os food trucks vem se potencializando em alguns estados brasileiros, após terem despontado nas ruas de São Paulo em 2013 (VIOL, 2017). Talvez para se adaptar mais ao gosto dos brasileiros de apreciar uma boa conversa enquanto como e bebe com amigos ou familiares, vem ocorrendo a disseminação de food park ${ }^{3}$ espaços fixos com a presença de food trucks permanen-

\footnotetext{
1"Food truck" vem do inglês literal "caminhão de comida", sendo compreendido no português do Brasil como "comida sobre rodas", "trailer de comida" ou ainda "cozinha sobre rodas" (Nota dos autores).

" "take away" é uma expressão do inglês que na terminologia da área da gastronomia significa que o cliente vai consumir o pedido fora do estabelecimento. A expressão faz oposição a "eat in", quando o cliente indica que irá consumir dentro do próprio estabelecimento comercial (Nota dos autores).

3"Food park" vem do inglês "parque de comida", sendo entendido como uma área gastronômica com a presença de food trucks (Nota dos autores).
}

tes ou itinerantes. Desta maneira, os consumidores possuem uma variedade gastronômica e a possibilidade de consumo dos produtos no próprio local, utilizando por mais tempo o espaço comercial.

A pesquisa teve relevância por tratar de um tema atual, em desenvolvimento teórico e que está diretamente ligado ao contexto socioeconômico contemporâneo. Pode contribuir, pois, para os envolvidos com pesquisas sobre mudanças em comportamentos sociais e tendências contemporâneas.

$\mathrm{O}$ escopo norteador do trabalho esteve vinculado às peculiaridades encontradas em duas capitais brasileiras que se utilizam de food parks como opção gastronômica de comida de rua. Para essa exposição, a seguinte questão de pesquisa foi levantada: que diferenças e semelhanças existem entre um food park na cidade de Fortaleza e um food park na cidade de São Paulo e seus consumidores?

Consequentemente, esse estudo teve por objetivo geral comparar o potencial gastronômico e o público de 2 food parks localizados em regiões brasileiras distintas. Como objetivos específicos, buscou-se diferenciar as estruturas físicas dos food parks; estabelecer o perfil socioeconômico dos consumidores; e contrastar o perfil gastronômico dos mesmos consumidores.

\section{A ARTE DE COZINHAR E SUAS IMPLICA- ÇÕES PARA O BRASIL}

O ser humano tem algumas obrigatoriedades no seu dia-a-dia. Dentre elas está a alimentação que garante a sobrevivência da espécie. Contudo, o pensamento que a comida está para o homem apenas como uma necessidade biológica apresenta-se obsoleto. Há muito tempo que a essa necessidade foi agregada o prazer de comer. Assim, surgiu a gastronomia aglutinando os sentidos do paladar, do olfato e da visão.

Há registros de iguarias criadas por gregos e romanos na Antiguidade. Deste modo, a arte de cozinhar com prazer não é uma ação moderna. Na verdade, a gastronomia é agregadora de múltiplos traços culturais e históricos ao longo da própria evolução do homem.

É importante diferenciar alguns termos relacionados ao assunto da pesquisa. A distinção se faz necessária para o entendimento do que foi herdado naturalmente do que foi herdado historicamente.

Primeiramente, "alimentar-se" não mantém a mesma conotação de "comer". De acordo com Santos (2005, p. 12), "os alimentos não são somente alimentos. Alimentar-se é um ato nutricional, comer é um ato social, pois constitui atitudes ligadas aos usos, costumes, protocolos, condutas e situações. Nenhum alimento que 
entra em nossas bocas é neutro". Pela própria reflexividade do primeiro verbo, percebe-se que a conotação do mesmo refere-se a uma ação para próprio benefício e está ligada à compulsoriedade. Enquanto que o verbo "comer" relaciona-se intrinsicamente às peculiaridades históricas e culturais de cada povo, sofrendo ainda influencia direta do tempo.

Os hábitos alimentares e elementos culinários podem variar por influências externas ou, até mesmo, decisões internas de cada sociedade ou grupo social. Para Santos (2005, p. 15):

Os hábitos e práticas alimentares de grupos sociais, práticas estas distantes ou recentes que podem vir a constituírem-se em tradições culinárias, fazem, muitas vezes, com que o indivíduo se considere inserido num contexto sociocultural que lhe outorga uma identidade, reafirmada pela memória gustativa.

Sobre os termos culinária e gastronomia, o primeiro também chamado de cozinha, Freixa e Chaves (2008) declaram que há uma diferença óbvia de sentido. Para eles, a primeira relaciona-se à arte de preparar comida e bebida através de práticas e técnicas específicas. Já a segunda vai além da prática e da técnica, alcançando tradições religiosas, sociais, preferências e conhecimentos dos povos. A gastronomia, pois, é um ramo que abrange a culinária.

Geralmente na gastronomia, preparar uma comida ou uma bebida proporciona prazer e momentos de lazer aos envolvidos, pois o processo encerra desde a socialização através das impressões associadas à degustação até relações culturais, quando há busca por novos produtos, especiarias, troca de receitas, etc (BRILLATSAVARIN 1989). Ampliando o alcance do termo, Coelho-Costa e Santos (2017) e Santos (2005, p. 143) são categóricos ao afirmar que "o caráter cultural da gastronomia permite a inclusão social e a reestruturação socioeconômica de sociedades, além de colocar a gastronomia como um bem simbólico da identidade de uma comunidade [...]”.

Instituições governamentais brasileiras e mundiais como o Instituto do Patrimônio Histórico e Artístico Nacional (IPHAN) e a Organização das Nações Unidas (ONU) já reconhecem as imaterialidades vinculadas às comidas e bebidas de destaque. A valorização aparece tanto em fatores objetivos como técnicas de preparo e ingredientes, quanto em fatores mais subjetivos como valores simbólicos que se agregam aos alimentos.

Se a ação de cozinhar é tratada como arte, então essa arte necessita de um estúdio. O estúdio da culinária ou da gastronomia é a cozinha. Como na pintura e na escultura, o estúdio para a combinação de sabores pode estar em ambientes fechados ou abertos. Como exemplos encontram-se as cozinhas residenciais, as cozinhas de restaurantes, e mais modernamente, as cozinhas ambulantes representadas pelos food trucks. Como declara Santos (2005, p. 21):

\begin{abstract}
Na cozinha, prevalece a arte de elaborar os alimentos e de lhes dar sabor e sentido. Nela, há a intimidade familiar, os investimentos afetivos, simbólicos, estéticos e econômicos. Em seu interior, despontam as relações de gênero, de geração, a distribuição das atividades que traduzem uma relação de mundo, um espaço rico em relações sociais, fazendo com que a mesa se constitua, efetivamente, num ritual de comensalidade. A cozinha é, portanto, um espelho da sociedade, um microcosmo da sociedade, é a sua imagem.
\end{abstract}

Agregando valor simbólico às cozinhas e aos processos que lá acontecem, esses ambientes também podem ser como territórios mágicos para a gastronomia e quem a realiza. Na visão de Assunção (2008, p. 11):

\begin{abstract}
A preparação da comida envolve a ocultação de alguns procedimentos. A cozinha é, portanto, o território do segredo. O segredo é uma forma de distribuição social do conhecimento que diferencia os indivíduos (entre aqueles que sabem e os que desconhecem) e cria uma relação social específica, uma relação de poder, regida por uma tensão que se dissolve na revelação.
\end{abstract}

No Brasil, a gastronomia está relacionada ao período da colonização, tendo suas origens nos índios, nos portugueses e nos escravos africanos, formadores da base do povo brasileiro. As cozinhas indígena, portuguesa e africana eram baseadas em elementos da terra como o milho, o feijão, a fava, a mandioca, a goiaba, entre outros. A colonização do Brasil foi a responsável pelo surgimento da gastronomia brasileira formal ou acadêmica. Óbvio que como essa área não ficou estanque. Depois da fusão de características desses três povos, posteriormente, a gastronomia se miscigena com a cultura de outros imigrantes (LEAL, 2005).

Desta maneira, a gastronomia brasileira tornou-se diversa a partir de uma riqueza étnica-cultural ímpar, com pratos produzidos originalmente pelo povo local e depois influenciados pelos imigrantes, estando assim em permanente processo de adaptação e reinvenção. Essa inquietação da gastronomia vem ocorrendo até os dias atuais por meio de inovações e tendências no que se referem a temperos, sabores, texturas e apresentação dos pratos.

Itens da cozinha local e internacional estão entrando cada vez mais em contato com um maior número de consumidores brasileiros. Esse fato ocorre pela propagação do comércio de alimentos em vias públicas, seja 
de maneira itinerante (vendedores ambulantes, food trucks, etc) ou de maneira fixa (food parks).

Países desenvolvidos ou em desenvolvimento industrial, comercial ou urbano como o Brasil são localidades propícias e acolhedoras para a comida de rua. Bezerra (2008) declara a herança do comércio culinário em vias públicas advinda da Costa Ocidental da África onde mulheres preparavam e vendiam comida nesses ambientes.

Quando é feita referência ao início da comida de rua no Brasil, retorna-se ao período da escravidão. Mesmo havendo liberação para o comércio ambulante realizado por mulheres, apenas escravas libertas ou buscando alforria se dispunham a ir às ruas vender iguarias, muitas vezes preparadas por suas próprias donas. A presença daquelas mulheres negras nas vias públicas não era bem recebida pelos brancos que compunham a maioria letrada e abastada da época (FERREIRA FILHO 1998). Iniciava-se assim um período de discriminação à comida de rua, como sinônimo de marginalidade, ratificada pela não aceitação das elites.

O hábito de comer fora de casa, frequente atualmente no cotidiano de vários brasileiros, há contribuído consideravelmente para mudanças mercadológicas. Tais mudanças se justificam devido a alguns fatores de destaque como a necessidade de mais membros da família no mercado de trabalho, o crescimento dos centros urbanos que distanciou escolas e empresas das residências dos trabalhadores ou a simples curiosidade por novos sabores oferecidos pelos ambientes gastronômicos contemporâneos.

Com isso, transcorreu também a diminuição do preconceito em relação à comida de rua, uma vez que houve uma melhora do produto final. Essa elevação passou obrigatoriamente por qualificação da mão de obra, marketing por meio da estilização dos pontos de venda e facilidade de acesso a ingredientes antes distante da maioria das pessoas.

O século XXI está, pois, representando a exposição ampla e a consolidação da gastronomia como expressão cultural dos povos, tendo como uma de suas principais expressões a comida de rua.

\section{FOOD TRUCKS COMO TENDÊNCIA DA GASTRONOMIA CONTEMPORÂNEA GLO- BALIZADA}

A história dos food trucks, maiores representantes da comida de rua, se inicia no final do século XVII nos Estados Unidos. Nessa época, pequenos comerciantes ofereciam comidas a trabalhadores nos subúrbios de al- gumas cidades americanas. Muito se transformou daquela época até os dias atuais (Quadro 1).

A comida simples vendida em carroças em locais sem a presença de outro comércio alimentício passou por adaptações e chegou à contemporaneidade com variedade gastronômica. Esse tipo de comida de rua é comercializado atualmente em veículos adaptados e em vários locais de centros urbanos espalhados pelos cinco continentes. As carroças passaram por um processo de estilização e se transformaram em food trucks de tamanhos variados.

Viol (2017) assegura que essas transformações necessitaram de planejamento por meio de análise de mercado e qualificação de mão de obra para ofertar algo que fosse de encontro aos desejos do público e alcançasse estabilidade mercadológica. Para ela, o sucesso vem ocorrendo pela união de qualidade e preços baixos se comparados a outros estabelecimentos gastronômicos tradicionais.

O boom dos food trucks se iniciou nos Estados Unidos em 2008. Por causa de uma crise econômica, vários restaurantes foram à falência. Com isso, profissionais do ramo investiram em um negócio menor, mas onde eles já possuíam know-how. No Brasil, o pioneirismo teve a cidade de São Paulo e o ano de 2013 como pontos iniciais desse tipo de comércio. Ainda hoje, é em São Paulo onde se localiza o maior polo de food truck do País (VIOL, 2017).

Desde a segunda metade século XX, o Brasil foi apresentado a um novo modelo de consumo alimentício: os fast-foods, que inseriram uma mudança cultural no País. Desse modo, com a ideia amadurecida de consumo rápido, barato e de boa qualidade, já no século XXI, consoante ao (SEBRAE, 2018), “[...] muitos empresários viram a possibilidade de empreender e expandir seus negócios ou abrir um primeiro restaurante num modelo diferente, com contato direto com o público, de baixo custo, sem necessidade de adquirir ponto comercial ou outros encargos". Diz-se, pois, que os fast-foods abriram as portas para a nova tendência de venda e consumo de comida de rua: os food trucks.

Para atender àqueles clientes que almejavam se alimentar unindo qualidade, rapidez, produtos diferenciados e possibilidade de permanência durante o consumo, foram criados os food parks, espaços destinados ao estacionamento de food trucks. Como diferencial, esses ambientes disponibilizam serviço com infraestrutura de banheiros, lavatórios, mesas e cadeiras. Alguns lugares oferecem ainda estacionamento e música ambiente ou ao vivo, o que tornam os food parks mais atrativos para os consumidores. 
TENDÊNCIAS COMPETITIVAS DA COMIDA DE RUA: ESTUDO COMPARATIVO ENTRE DOIS FOOD PARKS E SEUS CONSUMIDORES

Quadro 1: Evolução dos food trucks

\begin{tabular}{|c|c|c|}
\hline QUANDO & QUEM / ONDE & ACONTECIMENTO \\
\hline Final do século XVII & Pequenos comerciantes americanos & $\begin{array}{l}\text { Vendiam refeições em carroças nos } \\
\text { subúrbios americanos. }\end{array}$ \\
\hline 1866 & Charles Goodnight (Texas, USA) & $\begin{array}{l}\text { Responsável pelo boom da comida } \\
\text { de rua e criador do primeiro food truck } \\
\text { (carroça construída a partir de um } \\
\text { vagão velho de trem). }\end{array}$ \\
\hline 1872 & Walter Scott (Rhode Island, USA) & Criou o primeiro food truck estável. \\
\hline 1894 & Fornecedores de salsicha & $\begin{array}{l}\text { Vendiam seus produtos ao longo dos } \\
\text { campi das Ivy League Universities. }\end{array}$ \\
\hline 1936 & Oscar Mayer & $\begin{array}{l}\text { Cria o primeiro carrinho portátil } \\
\text { de cachorro-quente. }\end{array}$ \\
\hline 1950 & EUA & Nascimento do caminhão de sorvete. \\
\hline Final dos anos 1950 & EUA & Aparecem caminhões de batatas chips. \\
\hline Década de 1970 & $\begin{array}{l}\text { Invasão de imigrantes mexicanos } \\
\text { aos EUA }\end{array}$ & Popularização de caminhões de "tacos" \\
\hline 2008 & Los Angeles, EUA & $\begin{array}{l}\text { Food truck Koju BBQ usa as mídias } \\
\text { sociais para divulgar local, data e } \\
\text { horário de venda. }\end{array}$ \\
\hline 2013 & São Paulo, Brasil & $\begin{array}{l}\text { No Brasil, aparecem os pioneiros da } \\
\text { "comida sobre rodas" (food trucks). }\end{array}$ \\
\hline
\end{tabular}

Fonte: Baseado em Viol 2017) e no site ecomanda.com.br.

A era da globalização fez seu trabalho e aglutinou conceitos e receitas, espalhando rapidamente a ideia de que valeria investir em um caleidoscópio gastronômico. De acordo com Santos (2005, p. 22), "desta forma, a pós-modernização, embalada pela globalização, tem imposto novas formas de consumo alimentar, tem afetado o nosso paladar e os aportes nutritivos, trazendo novos padrões alimentares, novos costumes, hábitos e práticas alimentares".

Harvey (2009) afirma que a globalização serviu para difundir velozmente pratos de diversas regiões, fazendo que o conceito de comida exótica perdesse força. O que se encontra hoje tanto em restaurantes quanto na comida de rua são sabores mais acessíveis a um maior número de pessoas. Destarte, a cozinha global é degustada cotidianamente de forma mais tradicional ou de forma mais contemporânea por meio de serviço de entrega (delivery), pela comida de rua (food trucks) e até mesmo por serviços rápidos de alimentação (fast foods). É inegável, pois, a familiarização com a diversidade culinária.

Nesse contexto, frequentar estabelecimentos que oferecem tais inovações desperta interesses entre as pessoas que almejam apreciar a gastronomia de várias culturas, além de desfrutar de ambiente diferenciado, atrativo e potencialmente competitivo, característicos dos produtos encontrados em food trucks. Soma-se a esse fato, a profissionalização do comércio de food trucks, representada principalmente pelos conglomerados formadores dos food parks. O consumo de comida de rua está ligado agora não mais a incertezas sobre qualidade e higiene dos alimentos como no passado, mas apenas às opções de degustação devido a variedade encontrada nesses locais.

Nessa perspectiva, diante de novas opções de alimentos, receitas e influenciados pelos programas televisivos com temas voltados para a gastronomia mundial, os foods trucks ressurgiram como mais uma opção de alimentação na rua, abordando tendências gastronômicas atuais, miscigenando culturas e tradições. Conjuntamente, frente ao contexto socioeconômico nacional, os food trucks têm uma atuação importante. Haja vista as condições econômicas da atualidade, esse tipo de comércio pode contribuir para a geração de emprego e ajudar várias famílias a se manterem inseridos no mercado de trabalho, assunto, portanto, que excede o âmbito gastronômico. 


\section{PROCEDIMENTOS METODOLÓGICOS}

Para o desenvolvimento da pesquisa, optou-se pela técnica de abordagem por meio do método indutivo, caminhando de fatos singulares em direção a uma conclusão ampla sobre o tema. Portanto, as constatações particulares demonstradas pela análise dos ambientes e dos consumidores de um food park na cidade de Fortaleza e outro na cidade de São Paulo levaram à elaboração de generalizações sobre as tendências e estabilidade mercadológica desse nicho da comida de rua na atualidade.

Do ponto de vista dos objetivos, a presente pesquisa foi exploratória comparativa, por apresentar como finalidade uma maior familiaridade com o problema estudado. A comparação se caracterizou pelas semelhanças e diferenças de food parks de duas regiões brasileiras distintas e de seus consumidores.

De acordo com os procedimentos técnicos, iniciouse a pesquisa com uma exploração bibliográfica para apoiar o tema da gastronomia de rua. Após essa fase, foi realizada uma pesquisa de campo nos locais supracitados através da aplicação de um questionário. O questionário apresentou indagações de múltipla escolha e indagações se utilizando da Escala de Likert, onde os respondentes expressaram nível de concordância ou discordância e de frequência, numa escala numérica crescente de 1 a 5 .

Por concentrar-se na investigação de um único evento, essa pesquisa caracterizou-se como um estudo de caso. Considerou-se o estudo de caso apropriado porque tornou possível apreender e retratar a visão dos respondentes, além de que ocorreu um aprofundamento sobre alguns objetos temáticos sobre comida de rua.

$\mathrm{O}$ universo da pesquisa abrangeu os frequentadores dos 2 food parks escolhidos. Ambos os locais eram espaços sem controle de entrada e saída, dificultando o estabelecimento de um número preciso de usuários, por isso ficou decidido que o número conseguido na primeira hora de pesquisa seria o padrão para os outros dias. Sendo assim, chegou-se ao número de 14 respondentes na primeira hora do primeiro dia de pesquisa. Como os questionários foram aplicados em um sábado e em um domingo, o número total da amostra chegou a 56 questionários, sendo 28 o total de cada uma das cidades. A coleta de dados aconteceu primeiramente na cidade de Fortaleza, no último fim de semana de janeiro de 2017. Em São Paulo, os questionários foram aplicados no terceiro fim de semana do mês de março de 2017.

O primeiro food park pesquisado estava localizado na Avenida Washington Soares, 2400, no bairro Ed- son Queiroz, na cidade de Fortaleza 4 De acordo com o material de divulgação, o mesmo encontrava-se funcionando de quarta-feira a domingo, das $17 \mathrm{~h}$ às $23 \mathrm{~h}$, funcionando desde março de 2016. O outro food park localizava-se na cidade de São Paulo. O mesmo possuía duas entradas, ligando duas vias de bastante movimento no bairro da Consolação, próximo à Avenida Paulista. O food park paulistano podia ser acessado, então, pela Rua Augusta, 1291 ou pela Rua Frei Caneca, 1024. O horário de funcionamento desse food park estava divulgado como de domingo à terça-feira do meio-dia às $22 \mathrm{~h}$, e de quarta-feira aos sábados do meio dia à meia noite, funcionando desde janeiro de 2015.

A investigação apresentou uma análise de dados de caráter misto. A análise quantitativa se deu em razão da utilização de recursos estatísticos apresentados por meio de gráficos. Por sua vez, a análise qualitativa mostrou-se hábil para interpretar a realidade de modo mais amplo. Esse tipo de análise é indicado aos estudos sobre opiniões, valores ou crenças de determinado grupo. Procurou-se, desta forma, não um estudo exclusivamente numérico, pois reduziria o alcance das especificidades dos componentes da amostra da pesquisa.

\section{RESULTADOS E DISCUSSÕES}

Inicialmente foram descritas e comparadas a estrutura física e a oferta gastronômica dos 2 food parks em questão Em seguida foram analisados os resultados colhidos por meio do questionário aplicado com 28 consumidores de cada food park.

Entre os pontos comuns, foram encontrados extintores de incêndio, lixeiras e sanitários femininos e masculinos. Também, os dois food parks estavam localizados em vias de bastante movimento, incentivando e facilitando o acesso dos consumidores.

A respeito das particularidades de cada ambiente, ficou evidente que ofood park paulistano foi apenas organizado em uma área reaproveitada onde existiu uma ou mais edificações. Esse food park é um corredor com inclinação e com largura inconstantes, ligando a Rua Augusta à Rua Frei Caneca, no bairro da Consolação. Para o food park fortalezense, foi utilizado um terreno plano de forma retangular, propiciando uma visão generalizada do ambiente. Essa diferenciação de terreno propiciou ao ambiente da cidade de Fortaleza um aproveitamento para inserção de serviço de estacionamento gratuito e opções de lazer para crianças, a saber: fantasias, área gramada e playground com cuidadores. Esses

\footnotetext{
${ }^{4}$ Como não houve autorização formal para utilização dos nomes dos food parks, a diferenciação ocorrerá apenas pela localização (Nota dos autores).
} 
itens podiam ser mais um atrativo para os frequentadores ou apenas uma necessidade intrínseca do público da cidade nordestina (Figura 11.

O food park de Fortaleza apresentou número bem inferior de opções gastronômicas ao food park da cidade de São Paulo. Em Fortaleza, encontravam-se 8 caminhões de comida (food trucks) comercializando bebidas, doces, sanduíches, pratos de comida regional, de comida mexicana e árabe. Ao passo que em São Paulo havia 22 food trucks com gastronomia mexicana, síria, colombiana, árabe, peruana, argentina, churros, waffles, bebidas artesanais, entre outras. A diferença nas opções é facilmente compreendida, uma vez que a cidade de São Paulo é marcada por um caleidoscópio de povos provenientes de vários lugares. Com isso, o próprio paulistano tem mais oportunidades de enveredar na multiplicidade cultural por meio da gastronomia. Mesmo estando Fortaleza entre as capitais brasileiras mais habitadas no país, a comida local ainda é um grande atrativo de diversos estabelecimentos gastronômicos, fator ajudado também pela força turística da cidade. Além disso, a diversidade cultural nessa capital nordestina não pode ser comparada a uma das maiores metrópoles do mundo.

Em decorrência da oferta, os consumidores dispunham de cerca de 80 assentos na cidade nordestina, enquanto que a capital paulista possuía cerca de 200 . Para composição do número de assentos foram incluídos bancos individuais, bancos coletivos e cadeiras individuais.

Em relação aos consumidores da comida de rua desses espaços, semelhanças e divergências foram encontradas tanto no perfil socioeconômico quanto no gastronômico dos dois grupos.

Em nenhuma das cidades pesquisadas, os respondentes estavam no último grupo etário determinado pela pesquisa - 66 anos ou mais. Em ambas as cidades, o grupo mais expressivo foi o segundo, onde os pesquisados declararam estar entre 20 e 40 anos de idade. Fortaleza e São Paulo apresentaram cerca de $70 \%$ e $90 \%$ respectivamente de frequentadores nesse grupo. Por isso, a ida a food parks aparece como uma característica contemporânea de jovens que entram na fase adulta e estabelecem ou iniciam o período de autoafirmação social e financeira.

Os estados civis dos entrevistados ficaram entre solteiro(a), casado(a) e união estável. Porém, o número foi maior de solteiros e solteiras nas duas cidades pesquisadas. Fortaleza apresentou exatos 50\% desse estado civil, enquanto que São Paulo chegou a mais de $80 \%$. Os números direcionaram para um entendimento que es- ses lugares são democráticos em relação a receber famílias e relacionamentos já estabelecidos e servir também como ponto de encontro de pessoas sem relacionamentos oficializados que vislumbram uma oportunidade de encontrar amigos ou um parceiros para relacionamento amoroso.

O nível de escolaridade dos entrevistados flutuou entre o ensino médio incompleto até cursos de pósgraduação. Como diferença entre as cidades de Fortaleza e São Paulo está o fato de que a primeira apresentou mais frequentadores com curso de pós-graduação, $32 \%$ contra $11 \%$ dos entrevistados em São Paulo. Todavia a cidade de São Paulo apresentou 97\% dos entrevistados engajados no ensino superior ou já com formação nesse nível. Enquanto que Fortaleza apresentou 18\% dos entrevistados ainda no segundo nível de educação formal (ensino médio incompleto ou completo). Isso é um termômetro das diferenças socioeconômicas das duas cidades, uma vez que São Paulo é a maior e a mais populosa capital do Brasil e Fortaleza apenas a quinta em número de habitantes. Com isso, apresenta-se em São Paulo um maior número de instituições de ensino superior que preparam seus habitantes para o mercado de trabalho mais inchado e, consequentemente, mais concorrido.

As rendas dos respondentes de Fortaleza e de São Paulo apresentaram mais semelhanças que diferenças. As porcentagens dos 3 primeiros níveis, até 10 salários mínimos, foram muito aproximadas. Somente o número de pessoas com renda familiar acima de 10 salários mínimos foi maior em São Paulo, 25\% dos respondentes contra $14 \%$ dos pesquisados em Fortaleza. Notou-se também que apenas na cidade de Fortaleza, algumas pessoas, no total de $11 \%$ dos pesquisados, se recusaram a indicar uma opção para essa questão. Independentemente dessa abstenção, percebeu-se que classes sociais variadas frequentam esses lugares como estabelecimentos gastronômicos. Esse ponto foi também ratificado pela diversidade de nível educacional demonstrado no parágrafo anterior. A explicação que pode ser apontada como justificativa para a variação de frequentadores é que há opções capazes de atender a diferentes indivíduos com poder aquisitivo variado.

A respeito da autodenominação sobre o estilo de vida de cada pesquisado, a maioria dos participantes de ambas as cidades apontaram uma atitude moderna ao realizar refeições - $46 \%$ em Fortaleza e 36\% em São Paulo. Sendo assim, essa autodenominação combina perfeitamente com a proposta dos food parks de um modo geral - reunir em um único ambiente gastronomia diversificada acoplada a uma ação mercadológica 


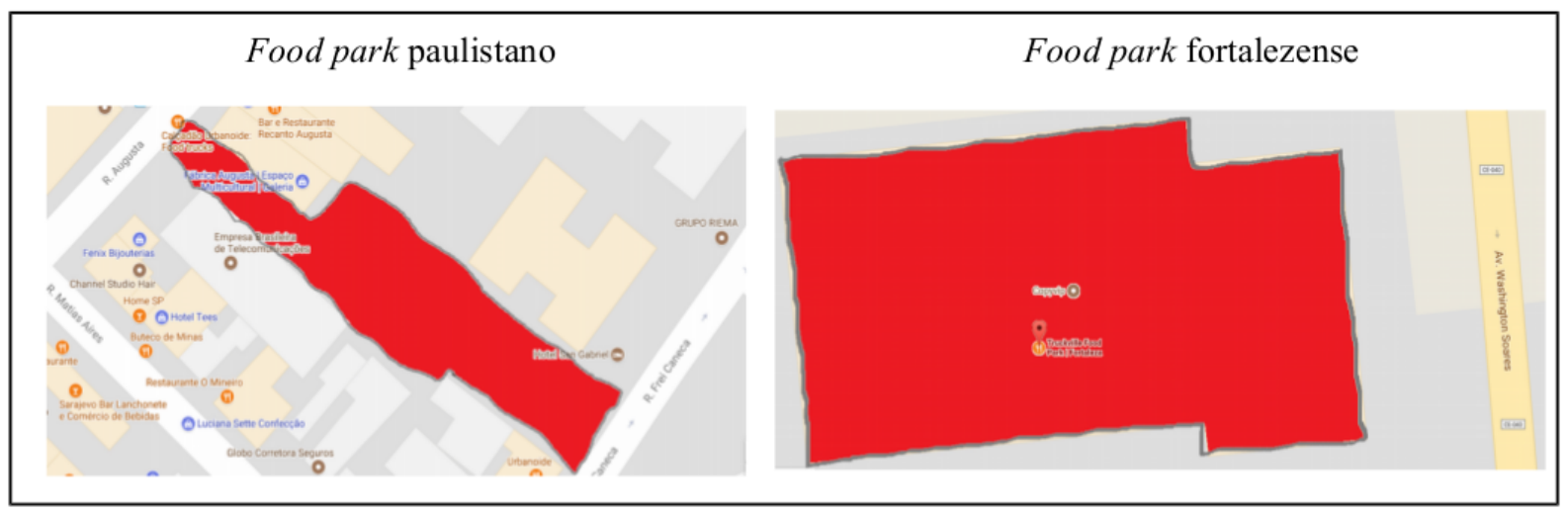

Fonte: Google Mapas (2017).

contemporânea, objetivando concorrer com nichos gastronômicos tradicionais como restaurantes, bares, etc. O estilo tradicional não foi, sobretudo, abandonado em nenhuma cidade. Porém em Fortaleza, mais participantes $(29 \%)$ se declararam favoráveis à comida tradicional, contra apenas $10 \%$ dos respondentes de São Paulo. Isso se deve ao teor cosmopolita encontrado em na capital paulistana. É inegável o contingente de povos que coabitam São Paulo, influenciando, e muito, os hábitos gastronômicos daquela metrópole. Outro ponto interessante a ser analisado com essa questão é o fato de nas duas cidades ter havido pluralidade de gostos para os tipos de comida oferecidos pelos food parks pesquisados.

Complementando a indagação anterior, encontramse dados sobre preferências para as comidas oferecidas nos food parks utilizados para a pesquisa (Figura 2). A gastronomia heterogênea proporcionada por esses ambientes é ampla, atraindo um público rico em especificidades gustativas.

As indicações não foram semelhantes nas duas cidades participantes da pesquisa. Em Fortaleza, a maioria de $61 \%$ indicou junk food 5 principalmente sanduíches e pizzas, como sua opção para ir àquele food park. As comidas gourmet foram a segunda preferência entre os pesquisados, fato esse que é aclarado por Fortaleza ainda se apresentar de maneira tímida no consumo da gastronomia gourmet, doces sendo a preferência da maioria, e por isso mesmo, está curiosa sobre esse modelo de gastronomia. Como contraponto estão os $3 \%$ indicados pelos pesquisados em São Paulo para a gas-

\footnotetext{
5"Junk food" é a expressão em inglês que significa "comida lixo" para se referir à comida com baixo valor nutricional. Nesse caso não importa a origem da comida ou da bebida, mas apenas o fato da comida não apresentar vários nutrientes (Nota dos autores).
}

tronomia gourmet. Provavelmente isso ocorreu por São Paulo já ser grande consumidora de "pratos gourmetizados”. São Paulo também apresentou mais variação nas indicações das preferências, trazendo também $29 \%$ dos entrevistados com múltiplas escolhas. São Paulo está claramente com atitude mais vanguardista na descoberta e experiência com comida de rua multicultural.

Sobre o panorama do período de consumo, ambos os públicos demonstraram tendência a idas aos fins de semana, 93\% dos pesquisados de Fortaleza e $82 \%$ dos pesquisados de São Paulo. Mesmo a aplicação dos questionários havendo ocorrido em finais de semana, a indagação era clara ao solicitar a preferência de dias. Consequentemente, devido à maioria expressiva apontando para um período da semana específico, ficou claro que esses espaços estão se incorporando cada vez mais nas opões de alimentação e diversão das cidades onde são instalados, principalmente aos sábados e domingos.

Como complementação da questão anterior, os pesquisados também responderam sobre horários favoritos. Fortaleza apareceu apenas com duas respostas das seis sugestões presentes no questionário. As noites foram apontadas como preferência de $75 \%$ do público. Os outros $25 \%$ ficaram para o horário conhecido como happy hour, normalmente entre $17 \mathrm{~h}$ e $19 \mathrm{~h}$. Já os respondentes de São Paulo demonstraram um leque maior de respostas. Mesmo assim os horários da tarde, happy hour e noite somaram $89 \%$ da preferência. Com isso, os food parks pesquisados são locais de consumo gastronômico no segundo e no terceiro períodos do dia geralmente desfrutados com o consumo de lanches, jantar ou simplesmente tomada de aperitivo.

A aceitação e fidelização a esse estilo contemporâneo de oferta de comida de rua perpassa a avaliação dos 


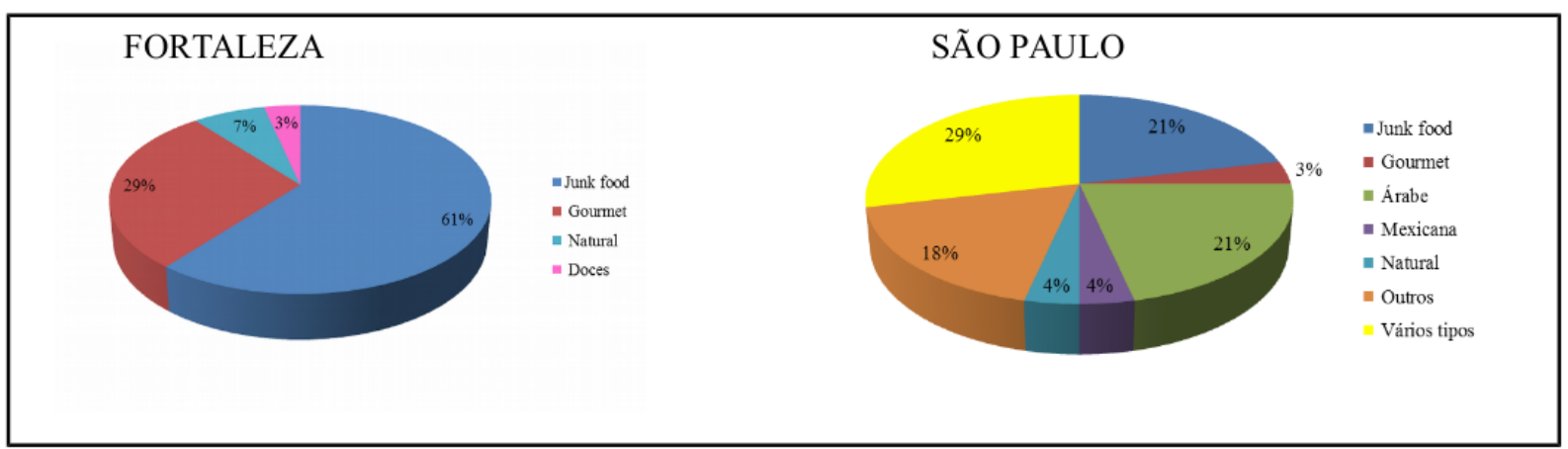

seguintes quesitos: aprovação dos tipos de comida oferecidos e curiosidade por outros locais com esse tipo de comércio. A partir daqui as respostas foram expressas pelo modelo da Escala de Likert, onde o respondente tinha que indicar o grau de concordância em uma escala de 1 a 5, a saber: $1=$ discordo totalmente; $2=$ discordo parcialmente; $3=$ indiferente; $4=$ concordo parcialmente e $5=$ concordo totalmente.

Quanto à aprovação das comidas oferecidas, mais de $90 \%$ de ambas as cidades concordaram, ainda que parcialmente, que os variados tipos de comida encontrados eram agradáveis. Essa aprovação ratifica o tipo de comércio realizado pelos food parks e promove estabilidade mercadológica desse nicho de comida de rua característico da era pós-moderna.

Juntaram-se aos dados anteriores os resultados da intenção de degustação das variedades gastronômicas dos food parks como forma de evitar a rotina alimentar, fazendo as pessoas migrar em busca de novos sabores (Figura 3). Embora os participantes de Fortaleza respondessem de forma mais mesclada, o que importou para a aprovação da comida e da bebida de rua oferecida nos locais da pesquisa foram as opções indiferente e com concordância parcial ou total. Sendo assim, houve $72 \%$ de aprovação na cidade de Fortaleza e a totalidade de respostas dos pesquisados em São Paulo.

Sobre a fidelização ao estilo contemporâneo de comida de rua ofertado por food parks e entendendo como respostas positivas apenas as mesmas opções do parágrafo anterior, São Paulo apresentou mais anuência que a cidade de Fortaleza. Em São Paulo, 75\% dos pesquisados não se importam em conhecer food parks, ainda que distantes de suas residências. Enquanto que em Fortaleza, o número caiu para $39 \%$ de pessoas que se mostraram indiferentes ou com concordância parcial e total. A diferença ocorre pela experiência da cidade de São Paulo com o processo de cosmopolitismo, através da representação de diversos povos oriundos dos cinco continentes e de várias partes do Brasil que coabitam o mesmo espaço urbano.

Avançando com o lado de fidelização ao estilo gastronômico de comida de rua, a última indagação foi sobre a substituição de um restaurante convencional pela a experiência de comer, beber e encontrar pessoas em food parks. Nesse aspecto, Fortaleza e São Paulo chegaram à mesma porcentagem $(82 \%)$ de respostas entre indiferentes ou com concordância parcial e total, embora o quantitativo das opções não tenham sido os mesmos (Figura 4). Posto assim, os dois grupos pesquisados estão abertos a novas experiências gastronômicas, se conectando principalmente com as tendências contemporâneas apresentadas por um mundo globalizado.

Como demonstrado pelas respostas dos pesquisados, os food parks são opções de alimentação com boas chances de continuidade no cenário contemporâneo de grandes cidades. A diversidade gastronômica oferecida nesses locais possibilita uma maior interação entre várias culturas. Os frequentadores são beneficiados com uma viagem através do paladar, que com certeza poderá aguçar outros sentidos. O conhecimento sem deslocamento físico é uma particularidade do mundo globalizado atual e que a cada dia abrange mais espaços da sociedade atual.

\section{CONSIDERAÇÕES FINAIS}

A vida na contemporaneidade apresenta uma profusão de invenções e descobertas direcionando os seres humanos a uma necessidade de adaptação. As inovações e descobertas ocorrem em qualquer esfera da sociedade - tecnológica, comercial e educacional, entre outras; que são advindas, em parte, da globalização.

A diversidade cultural se expressa por meio de crenças, danças, vestuário, línguas e da gastronomia também. Como parte do processo de globalização e de 


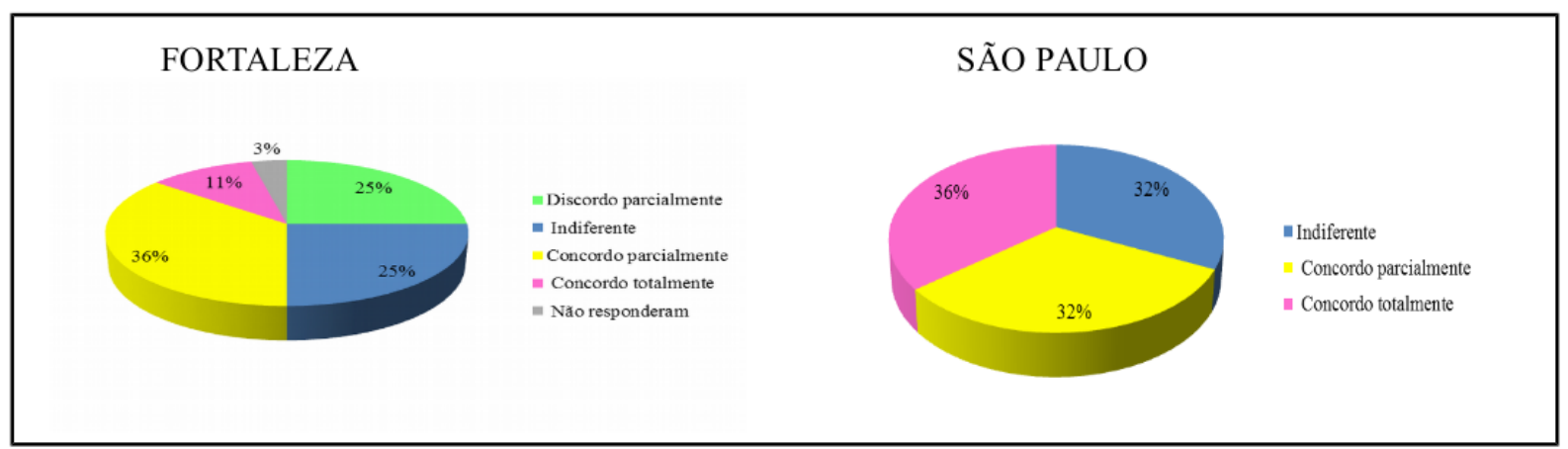

Figura 4: Substituição de restaurantes convencionais por food parks.

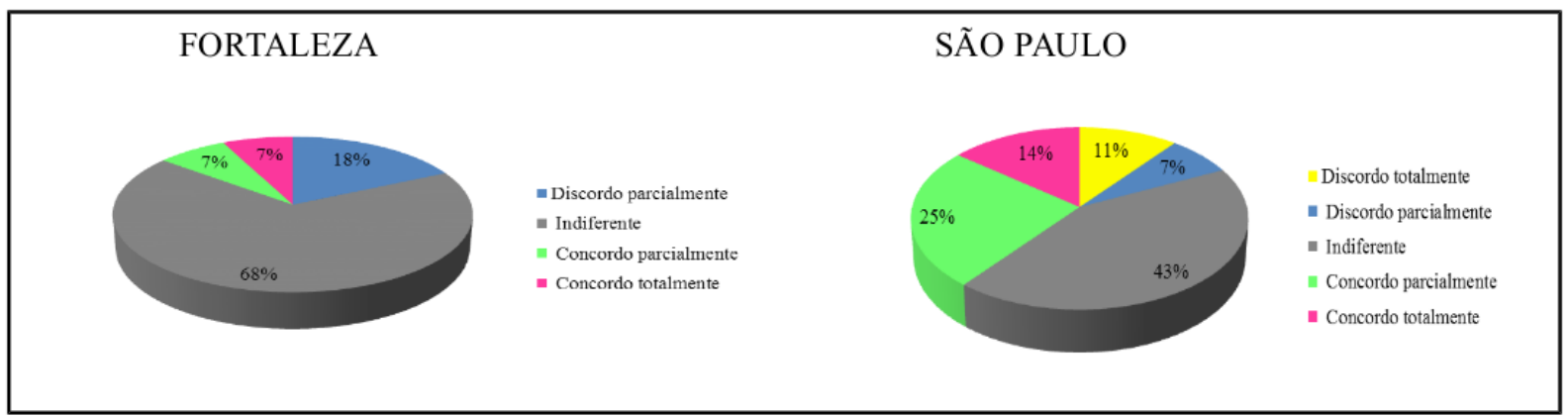

respeito às mais variadas características dos povos, a gastronomia pode ser utilizada como ferramenta de reconhecimento de sabores, de texturas, de ingredientes e de criatividade.

Percebem-se culturas de todas as partes do mundo influenciando diretamente os costumes dos brasileiros, indo desde modos de se comportar até o modo de se alimentar. O que comer e onde comer são dois questionamentos que atualmente podem ser respondidos por meio dos food parks, ou mesmo food trucks, espalhados por várias cidades do País. Esse nicho da comida de rua aparece no cenário gastronômico como um fator agregador na ratificação e disseminação de culturas.

A pesquisa atingiu os objetivos propostos por meio da comparação dos dois food parks escolhidos e de seus frequentadores a fim de detectar a tendência mercadológica desse tipo de comida de rua. Foram demonstradas semelhanças e diferenças estruturais entre o food park em Fortaleza e o food park em São Paulo. Entre as semelhanças estavam itens de segurança e de higiene. Já as diferenças foram notadas principalmente na quantidade de food trucks, assentos e consequentemente opções gastronômicas, com o espaço paulista apresentando número mais elevado. Contudo, estava inserido, apenas no primeiro food park, itens de comodidades para clientes como estacionamento e espaço infantil.

Em relação ao perfil socioeconômico, a maioria dos pesquisados era formada por jovens solteiros com renda familiar até 10 salários mínimos e com nível superior. Não foram encontradas nesse quesito grandes discrepâncias entre os públicos das duas cidades.

Para compor o perfil gastronômico, apontou-se multiplicidade de preferências entre itens locais e internacionais, gourmetizados e junk food, entre outros. As respostas também indicaram a fácil aceitação desse tipo de gastronomia, chegando a ser cogitada a diminuição da frequência a restaurantes convencionais em detrimento da comida de rua oferecida nos food parks. A variedade de produtos em um só lugar é o que consegue estabelecer a comida de rua comercializada nesses ambientes no cenário econômico atual, ratificando esse tipo de comércio e demonstrando sua força mercadológica.

Esse hibridismo cultural demonstrado nos últimos anos pode ser encarado como um ponto positivo para a globalização de ideias e de individualidades. A gastronomia se inclui totalmente nessa ação, impulsionada pela disseminação dos restaurantes fast food, do serviço 
de entrega em domicílio e dos food trucks e food parks. As características de cada povo estão presentes nesse tipo de comércio de comida de rua, uma vez que já apresenta estabilidade mercadológica. Essa tendência serve para aumentar o conhecimento e o respeito às diferenças. Diferença não é erro, rejeição sim. Diferença não é ruim, falta de interesse de novos conhecimentos sim.

\section{REFERÊNCIAS}

ASSUNÇÃO, V. K. Comida de mãe: notas sobre alimentação e relações familiares. 2008. Disponível em: <http://www.seer.ufu.br/index.php/neguem/ article/view/2110> Acesso em: 17 set. 2017.

BEZERRA, A. C. D. Alimentos de rua no Brasil e saúde pública. 1. ed. São Paulo: Annablume, 2008.

BRILLAT-SAVARIN, J. A. A fisiologia do gosto. 1. ed. Rio de janeiro: Salamandra, 1989.

Coelho-Costa, E. R.; SANTOS, M. S. F. d. Cultura e gastronomia no turismo: considerações sobre patrimônio cultural gastronômico. In: Marketing e gastronomia: estratégias para turismo e hotelaria. Fortaleza: IFCE, 2017. p. 127-148.

ECOMANDA. Ecomanda.com.br. 2019.

Disponível em: <http://www.ecomanda.com.br/blog/ comida-de-rua-historia-food-truck $>$ Acesso em: 18 mar. 2019.

FERREIRA FILHO, A. H. Desafricanizar as ruas: elites letradas, mulheres pobres e cultura popular em salvador 1890-1937. Afro-Ásia, v. 1, n. 21-22, p. 239-256, 1998.

FREIXA, D.; CHAVES, G. Gastronomia do Brasil e no mundo. 1. ed. Rio de Janeiro: Senac Nacional, 2008.

HARVEY, D. The condition of postmodernity. In: CHAVES, J. (Ed.). Mulheres com negócios de comida. Espanha: Universidade de Vigo/ servizo de publicación, 2009.

LEAL, M. L. M. S. A história da Gastronomia. 1. ed. Rio de janeiro: Senac Nacional, 2005.

SANTOS, C. R. A. A alimentação e seu lugar na história: os tempos da memória gustativa. História: questões \& debates, v. 42, n. 1, p. 11-31, jan.-jun. 2005 .
SEBRAE. Food truck: hora de investir em um novo modelo de negócio. 2018.

Disponível em: <http://www.sebrae.com.br/sites/ PortalSebrae/artigos/food-truck-uma-nova-tendencia, d128e6f7c633c410VgnVCM2000003c74010aRCRD> Acesso em: 18 mar. 2019.

VIOL, C. A origem e a evolução dos food trucks no mercado brasileiro. 2017. Disponível em: $<$ http://www.hfurbanismo.com.br/gastronomia/ a-origem-e-a-evolucao-dos-food-trucks-no-mercado-brasileiro/ $>$ Acesso em: 21 set. 2017. 